\title{
Endoscopic submucosal dissection as a diagnostic procedure for a giant submucosal "sausage" causing dysphagia
}

A 56-year-old woman was referred to our endoscopy unit for severe dysphagia with weight loss. A large sessile submucosal lesion was discovered during gastroscopy at $25-40 \mathrm{~cm}$ from the dental arches. Endoscopic ultrasonography (EUS) revealed a submucosal lesion not invading the muscular layer with a cystic component. The findings of EUS-guided fine needle aspiration (EUS-FNA) were inconclusive. Computed tomography (CT) confirmed a large hypodense lesion obstructing the middle and lower third of the esophagus ( $\triangleright$ Fig.1). Therefore, we chose a diagnostic endoscopic submucosal dissection (ESD) to avoid morbid surgery for a potentially benign lesion.

First, a proximal incision was made to create a tunnel using a T-type HybridKnife (Erbe Elektromedizin, Tübingen, Germany) after glycerol solution had been injected. Distal incision was not performed so that we could close the tunnel to avoid complications should the resection fail. Distal progression with the tunneling technique was difficult so we made lateral incisions and applied the clip-with-line traction technique. An IT-Knife (Olympus, France) was finally used for distal incision because of constraints owing to specimen size. The resection was en bloc, but the specimen fell into the stomach. We fragmented the lesion with a 25-mm hot snare (Olympus) and extracted the pieces with a basket snare (US Endoscopy). The resection site was clean ( $\vee$ Video 1 ). Histopathological analysis revealed a giant cystic lymphangioma ( $\mathbf{F i g . 2}$ ). The patient remained well 5 months later, with no residual dysphagia, and a follow-up gastroscopy was normal.

Esophageal lymphangiomas are very rare, with around 30 reported cases. En-

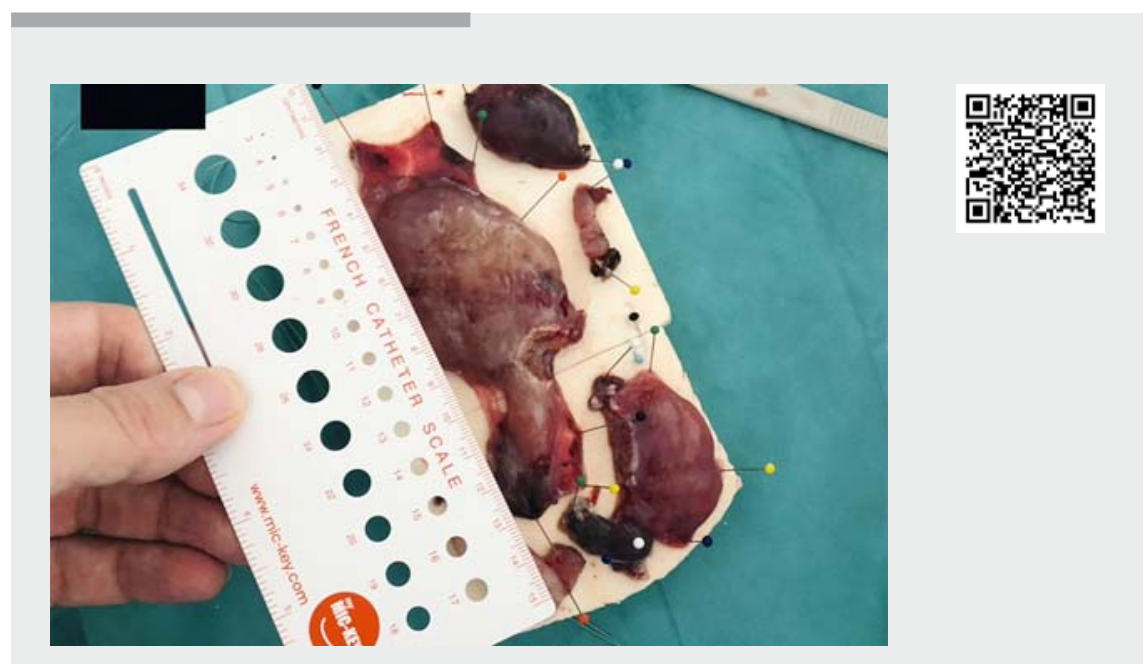

Video 1 Endoscopic submucosal dissection of a giant cystic lymphangioma in the esophagus.

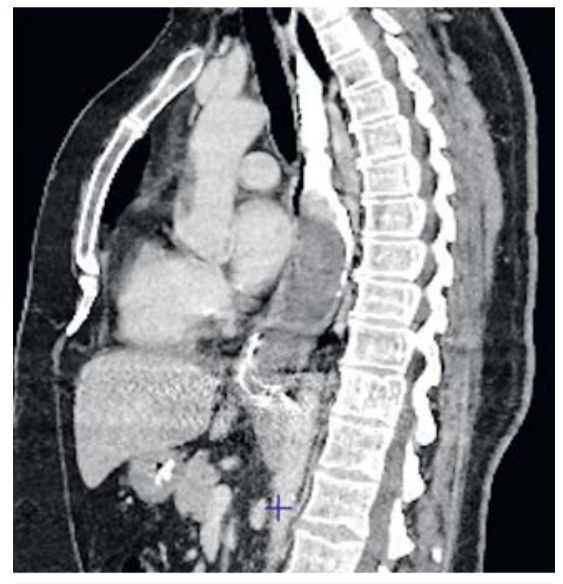

- Fig. 1 A sagittal computed tomography scan image showing a giant esophageal submucosal lesion.

doscopic resection has been proposed when the diagnosis is in doubt or to treat the symptoms for lesions smaller than $2.5 \mathrm{~cm}$ [1-3]. Until now, larger lesions

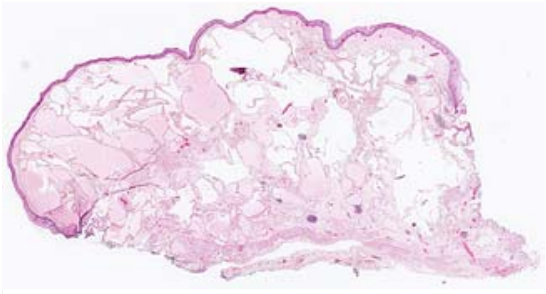

Fig. 2 Histopathology of the lesion showing dilated or cystic lymphatics in the submucosa, as well as focally in the muscularis mucosae.

have been treated by radical surgery. We suggest ESD as a diagnostic and therapeutic procedure for these submucosal lesions. Should the procedure fail, any additional surgery will not have been compromised by this minimally invasive procedure.

Endoscopy_UCTN_Code_TTT_1AO_2AC 
None

The authors

Martin Dahan' ${ }^{1}$, Anne Guyot ${ }^{2}$, Aurelie

Charissoux ${ }^{2}$, Marion Schaefer ${ }^{3}$, Romain

Legros $^{1}$, Mathieu Pioche ${ }^{4}$, Jérémie Jacques ${ }^{1,5}$

1 Service d'Hépato-gastro-entérologie, $\mathrm{CHU}$ Dupuytren, Limoges, France

2 Service d'anatomopathologie, $\mathrm{CHU}$ Dupuytren, Limoges, France

3 Service d'Hépato-gastro-entérologie, $\mathrm{CHU}$ de Nancy, Vandoeuvre-lès-Nancy, France

4 Service d'Hépato-gastro-entérologie, Hôpital Edouard Herriot, CHU Lyon, France

5 BioEM, XLim, UMR 7252, CNRS, Limoges, France

\section{Martin Dahan, MD}

Service d'Hépato-gastro-entérologie, CHU Dupuytren, 2 avenue Martin Luther-King,

87042 Limoges, France

martindahan@hotmail.fr

\section{References}

[1] Luo D, Ye L, Wu W et al. Huge lymphangioma of the esophagus resected by endoscopic piecemeal mucosal resection. Case Rep Med 2017. doi:10.1155/2017/5747560

[2] Arashiro M, Satoh K, Osawa H et al. Endoscopic submucosal dissection of esophageal lymphangioma: a case report with a review of the literature. Clin J Gastroenterol 2010; 3: $140-143$

[3] Barbosa M, Ribeiro PM, Cotter J. Oesophageal lymphangioma: an exceedingly rare tumour. BMJ Case Rep 2015. doi:10.1136/bcr2015-209605

\section{Bibliography}

DOI https://doi.org/10.1055/a-0929-3072

Published online: 1.7.2019

Endoscopy 2019; 51: E368-E369

(c) Georg Thieme Verlag KG

Stuttgart · New York

ISSN 0013-726X

\section{ENDOSCOPY E-VIDEOS}

https://eref.thieme.de/e-videos

回局 Endoscopy E-Videos is a free

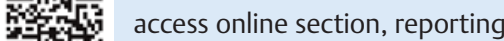
回: on interesting cases and new

techniques in gastroenterological endoscopy. All papers include a high quality video and all contributions are freely accessible online.

This section has its own submission website at https://mc.manuscriptcentral.com/e-videos 